\title{
La extradición: una herramienta para el fortalecimiento de la imagen estatal colombiana durante las presidencias de Betancourt (1982- 1986), Barco (1986-1990), Pastrana (1998-2002) y Uribe (2002-2010)
}

\author{
Nicolás Cardona Londoño* \\ (nicolascardonal@hotmail.com)
}

\author{
Daniel Tellez Salgado** \\ (tellez.max@hotmail.com)
}

\author{
Juan José Serrano Rojas ${ }^{* * *}$ \\ (juan.serrano@correo.icesi.edu.co)
}

Artículo de investigación recibido el 26/11/2015 y aprobado el 19/02/2016.

\begin{abstract}
Cómo citar este artículo:
CARDONA LONDOÑO, Nicolás; TELlEZ SALGADO, Daniel; y SERRANO ROJAS, Juan José (2016). "La extradición: una herramienta para el fortalecimiento de la imagen estatal colombiana durante las presidencias de Betancourt (1982-1986), Barco (1986-1990), Pastrana (1998-2002) y Uribe (2002-2010)". En: Trans-pasando Fronteras, Núm. 9, pp. 49-75. Cali, Colombia: Centro de Estudios Interdisciplinarios, Jurídicos, Sociales y Humanistas (CIES), Facultad de Derecho y Ciencias Sociales, Universidad Icesi.
\end{abstract}

\section{Resumen}

Este artículo parte una revisión bibliográfica sobre el tema de la extradición, propone una visión y aporta una herramienta analítica que permite ampliar el debate alrededor de este tema, en el cual, de manera general se encuentran tres posiciones en donde se pueden ubicar a diferentes autores que han abordado esta temática. Se analizan los periodos presidenciales de Betancourt (1982-1986), Barco (1986-1990), 
Pastrana (1998-2002) y Uribe (2002-2010), se intentará establecer un dialogo entre los discursos que fundamenta la identidad del Estado colombiano.

\section{Palabras clave:}

Extradición, Política estatal, Colombia, Estado, Narcotráfico

\section{Introducción}

Indiscutiblemente, las dinámicas del narcotráfico junto a las particularidades de nuestro conflicto armado, presentan importantes retos para la construcción del Estado, tanto a nivel interno como a nivel externo, no sólo por el hecho de que el gobierno afronta grandes dificultades para combatir estos fenómenos y reclamar con éxito el monopolio legítimo de la violencia, sino también porque estos han cooptado partes importantes del Estado mismo (López, 2012). Frente a estas circunstancias, el gobierno colombiano se apropia, crea y adquiere diferentes herramientas, que por su envergadura deben ser abordados a través de su complejidad con políticas públicas con objetivos suficientemente amplios.

Sin embargo, el narcotráfico y el conflicto armado no pueden ser entendidos como fenómenos que únicamente están presentes e impactan el territorio colombiano. Autores como Palacios (2012) y Tokatlian (2000) parten de la idea de que las problemáticas colombianas respecto a seguridad y orden público, por sus propias dinámicas y la naturaleza del mercado ilegal, rompen las fronteras nacionales y generan impactos considerables en actores internacionales. En clave de lo anterior, los diferentes gobiernos colombianos se ven en la necesidad de incluir en su agenda internacional, como prioridad, la cuestión del narcotráfico y el conflicto armada cada vez más enmarcado en el fenómeno del terrorismo y la misma cuestión de los estupefacientes (Borda, 2007). Frente a esto aparece una doble implicación: por un lado, el conflicto y el narcotráfico se convierte en una oportunidad para formular una política exterior amplia alrededor de esto, y por otro lado, es el Estado quien debe responder a las presiones internacionales y sistémicas que cada vez más exigen a Colombia una respuesta efectiva a estas situaciones, tanto por su afección a los otros estados como su afección al poder y posición de Colombia en el sistema (Palacios, 2012; Tokatlian, 2000). 
Es en este contexto donde la extradición aparece como una de las herramientas por excelencia de la lucha contra el narcotráfico, y más recientemente contra los grupos armados al margen de la ley. Oficialmente, la cancillería colombiana define la extradición como un mecanismo de cooperación internacional que busca combatir el crimen y la impunidad, y cuya expresión formal es la entrega de un sindicado o condenado por parte del Estado colombiano a otro Estado (Colombia, 2014).

Ahora bien, la extradición no puede ser vista como un simple mecanismo que mezcla cooperación con derecho penal internacional. La extradición debe ser también abordada a partir de sus dimensiones políticas y las consecuencias que tiene a nivel externo e interno. Esta decisión, que implica un vínculo de Colombia con actores internacionales, y que además requiere procesos establecidos con anterioridad, debe ser analizada con más profundidad. La anterior preocupación nace de la ausencia de trabajos y disertaciones que tengan como unidad de análisis la extradición y donde no únicamente sea abordada como una parte menor de un fenómeno global. Es por esto que se considera pertinente abordar la extradición, proponiendo una visión sobre esta, y aportando una herramienta analítica que permita ampliar el debate alrededor de este tema.

Bajo esta preocupación, este ensayo parte una revisión bibliográfica del tema. En esta revisión se encuentran tres posiciones a nivel general donde se pueden ubicar a los diferentes autores que han abordado esta temática.

Inicialmente, se encuentra una posición en la cual se establece que la extracción, como herramienta política y de política exterior, es producto de varios factores internos, y por lo tanto, es el gobierno colombiano quien ha decidido usarla (o no usarla) para cumplir diferentes objetivos. Sin embargo, este mismo gobierno es quien debe afrontar los retos a nivel interno para que la extradición sea fácilmente adelantada y aceptada.

En esta posición encontramos a autores como Buitrago (2006), quien en su análisis histórico de la política exterior colombiana del siglo XX intenta romper la idea de que todas las decisiones del país son producto de su posición periférica y su dependencia a los grandes poderes hegemónicos. Buitrago señala que los diferentes gobernantes colombianos intentan aumentar la capacidad de negociación del país a través de mecanismos que logren estrechar relaciones sin entrar en conflicto directo con otros países. En este contexto la extradición, señala el autor, es una evidencia de cómo Colombia decide sobre su política 
exterior en un intento por mejorar sus relaciones y solventar ciertos problemas internos. Argumenta él, que la idea de que la extradición sea una imposición es errada, ya que los primeros gobernantes que la llevaron a cabo en la contemporaneidad durante la década de 1980 y principios de los 90s (principalmente Betancourt, Barco y Gaviria), lo hicieron en un momento que el autor caracteriza como "Respice Similia", donde se buscaba fortalecer ante todo las relaciones con Estados cuya ubicación en el sistema internacional era similar a la de Colombia. El autor finalmente indica que a pesar de las semejanzas entre políticas gubernamentales, no se puede entender la política exterior como un continuo homogéneo, donde las rupturas son constantes y donde las coyunturas internas tienen un peso importante (Buitrago, 2006). Acá se resalta, por ejemplo, que es imposible pensar en la extradición sin las fuertes crisis de seguridad que vivió Colombia a raíz del narcotráfico.

Por otro lado, Moreno (2012) afirma que el Estado colombiano utiliza la extradición de manera irresponsable al facultar actores externos como EE.UU. para efectuar prácticas que no conllevan a una real cooperación judicial internacional. El gobierno no sólo manipula la ley, sino que utiliza la extradición como forma de lucha en contra de la guerrilla y por consiguiente convierte a la justicia norteamericana en un actor más frente a los problemas de orden público, aunque se enfatiza que esta decisión se toma por consentimiento propio del gobierno colombiano.

Además, se realiza una crítica contundente al procedimiento de extradición, haciendo un recuento de los connacionales extraditados y las limitaciones que tienen en un inicio al no contar con garantías, pero todo ello justificado en la medida en que el sistema judicial nacional no presenta una solides institucional suficiente para llevar a cabo un juicio, condena y custodia adecuados, y por lo tanto, incapaz de resolver las diferentes problemáticas. En la actualidad la cooperación judicial internacional, menciona la autora, plantea la necesidad de reestructurar el sistema judicial y político de los países implicados, con el objetivo de garantizar una real cooperación y no una limitación a los intereses nacionales. Es por esto que, aunque la debilidad institucional interna sea el factor más relevante para la existencia de la extradición, ésta no puede seguir siendo una excusa para que Colombia renuncie a su autonomía internacional. Por lo tanto, si Colombia sigue tomando este tipo de decisiones sin un análisis a largo plazo, terminará por permitirle al actor externo implementar sus políticas en un escenario donde el Estado colombiano queda relegado. 
La Fundación Ideas para la Paz (2009) hace un análisis de la extradición como posible herramienta política. En clave de lo anterior, se habla de la extradición como producto de decisiones internas del Estado y los diferentes gobiernos, en este caso el de Álvaro Uribe Vélez, en el marco del proceso de justicia y Paz. Por ende, este artículo se cuestiona si en Colombia la extradición se convirtió en una herramienta política y jurídica que facilita los objetivos gubernamentales (Fundación Ideas para la Paz, 2009). Al plantearse lo anterior, desarrollan un análisis de cómo el gobierno actuó en torno a la relación con Estados Unidos, y el tratado de extradición vigente.

La extradición aparece claramente como un producto de las decisiones internas, y en cierta medida, como una herramienta política del gobierno para lograr desarrollar un proceso de negociación con grupos paramilitares. Éstos tenían orden de captura, pero en el proceso se les plantea que aquel que cumpla con las condiciones del proceso podría evitar la extradición; es decir, "el gobierno utilizó la extradición como herramienta para mantener a los paramilitares en la mesa de negociación" (Fundación Ideas para la Paz, 2009:2). A nivel interno, la extradición se adopta como un medio para la eficacia del proceso. A pesar de que hay solicitudes de extradición por parte de Estados Unidos, se dejan por el momento, de lado algunas para seguir con éste. Pero también, otras condiciones internas como la crisis institucional por la relación entre políticos y paramilitares, y la creación y manejo de grupos paramilitares guiados desde las cárceles del país hacen que el gobierno decida extraditar a miembros paramilitares, lo cual genera tensión interna por la preocupación de que éstos no den los testimonios. Sin embargo el gobierno demuestra que la extradición, como resultado de una decisión interna, en el momento que afirma que Justicia y Paz y la extradición no son procesos excluyentes, por ende, es una herramienta necesaria para desarrollar una negociación interna teniendo en cuenta los antecedentes mencionados.

Se puede decir que los principales aportes de estos tres autores es la explicación de cómo el desarrollo histórico de la extradición está fuertemente relacionado con decisiones políticas que implican tensiones internas e intentos por afrontar retos coyunturales. Sin embargo, un vacío importante en estos autores es que no mide el impacto que tiene esta decisión para su política exterior y en general para sus relaciones internacionales. Además, no se explica a fondo las razones por las cuales la extradición haya tenido tantos obstáculos internos. 
Una segunda posición encontrada es la que establece que la extradición es un mecanismo impuesto por Estados Unidos desde la aparición de la guerra contra las drogas. En este contexto, esta potencia condiciona su ayuda económica y jurídica a partir del cumplimiento y desarrollo de varias políticas que están dentro del proyecto que intenta erradicar el problema de las drogas desde los países y actores ofertantes y productores. Posteriormente, la extradición aparece como una de las herramientas que muestra el compromiso de los diferentes países respecto al problema mundial del terrorismo.

En esta posición se inscribe Pardo (1995) quien señala que una muestra de que la extradición es impuesta y condicionada, es el sistema de incentivos y castigos que tiene Estados Unidos frente a los países participantes de su política antidrogas. Acá sobresale el mecanismo de certificación que tiene este país para indicar que actores han cumplido con sus compromisos adquiridos. Él señala que del resultado de esa certificación depende fuertemente la continuidad y la cantidad de la asistencia económica de Estados Unidos. Además, este mecanismo de certificación también es una radiografía de la situación de las relaciones entre países y de las exigencias que está requiriendo esta potencia.

Pardo señala que hay tres tipos de certificación. La desertificación, la certificación sin justificación y la certificación por interés nacionales. Colombia, por su lado, ha sido certificada por intereses de seguridad nacional. La extradición gana un peso importante porque, según el autor, es uno de los objetivos que Colombia más cumple, y a pesar de los continuos altos índices de producción de estupefacientes y la fuerte corrupción gubernamental, Colombia sigue entregando a la justicia americana los diferentes ciudadanos requeridos. Por lo tanto, concluye el autor, la extradición permite la certificación, y esta última permite continuar con el apoyo económico y político que Colombia requiere y que es condición necesaria para elaborar planes de ayuda (Pardo \& Cardona, 1995) como el Plan Colombia (aunque este no es el ejemplo del autor).

El aporte principal de Pardo es lograr mostrar evidencia empírica que relaciona los mecanismos de presión de Estados Unidos, la decisión de Colombia de adelantar la extradición y las repercusiones en instituciones internacionales. Sin embargo, no explica porque en algunos casos una no certificación no repercute en las ayudas económicas, lo que deja un vacío para comprender el peso real de estos mecanismos. 
Bajo esta misma posición, González (2014) se cuestiona si la extradición (entre Colombia y Estados Unidos) se presenta como mecanismo de cooperación internacional o como instrumento de política Norteamericana. Por ende, analiza la extradición en sí misma, es decir, cómo la han desarrollados los Estados, y cuál ha sido la relación entre estos dos países en torno a este tema. Él afirma que la extradición principalmente radica alrededor de las acciones que están asociadas al narcotráfico, donde Estados Unidos tiene una mayor ventaja técnica-investigativa para enfrentarse a este fenómeno (González, 2014). Además, Estados Unidos logra en Latinoamérica tener gran injerencia para realizar acciones en contra de lo que genere un posible riesgo para su territorio; lo que va creando una relación asimétrica mayor entre USA y Latinoamérica (en este caso Colombia). Por último, la coacción ejercida mediante sanciones de carácter internacional ejercida por parte de los Estado Unidos para vincular al estado Colombiano a sus intereses de extradición, permite establecer un puente entre las políticas internacionales de carácter individual de los Estado Unidos (González, 2014:20) El autor se acerca más a que la extradición es una decisión influenciada por Estados Unidos, y ve en ella y en otras políticas antidroga la capacidad de que sus "órganos internos que con proyección internacional irrumpan diplomáticamente en otros países con fines operativos y tácticos" (González, 2014:21), aportando no solo al debate de la extradición y la lucha contra las drogas, sino también a las lógicas generales de la política exterior americana.. Sin embargo, son pocas las evidencias empíricas que se presentan, además de que se pasa rápidamente del plano colombiano al latinoamericano sin hacer un ejercicio comparativo de lo que ha pasado con otros estados.

Finalmente, la última posición hallada es la que señala cómo la extradición es producto de factores tanto internos como externos, y que no se puede entender este proceso sin estas dos dimensiones. Además, se plantea que la extradición no hubiera sido posible sin la presión de Estados Unidos en el marco de la lucha contra las drogas y el terrorismo, y los diferentes eventos coyunturales que demostraron la debilidad del Estado colombiano para combatir los diferentes problemas de orden publica, y donde la política exterior colombiano fortalece sus vínculos con Estados Unidos cuando el conflicto se encrudece.

En el marco de esta posición aparecen autores como Zuleta (2010). Este autor señala que la extradición se termina reglamentando, por un lado, por la presión que empezó a generar Estados Unidos, principalmente desde la administración Reagan, donde la aplicación de 
las políticas antidrogas y la lucha bilateral contra los carteles aparece como una condición sine qua non para el aumento y la permanencia de los recursos económicos provenientes de Estados Unidos. Además, esta presión está acompañada por un acondicionamiento del apoyo de este país a Colombia frente a los organismos internacionales, donde, por ejemplo, resalta el respaldo que existió para los préstamos en el Banco Mundial.

Por otro lado, Zuleta señala que la extradición termina reglamentándose debido a la aparente debilidad institucional que era insostenible a finales de la década de 1980. En este procesos se resaltan tres momentos. El primero corresponde al vacío jurídico y la incapacidad institucional para establecer un procedimiento claro durante los ochentas, y donde sobresale el constante papel de la Corte Suprema en las diferentes situaciones. Un segundo momento es la constituyente del 1991 quien prohíbe, por diferentes presiones, la extradición de nacionales. Sin embargo, el recrudecimiento del conflicto y la incapacidad por reducir la cantidad de droga producida y exportada a mediados de los noventas, lleva a que en el año de 1997, el senado colombiano apruebe finalmente la extradición que actualmente rige. El último momento señalado es la extradición posterior al 2001, donde aparece el término narcoterrorismo y aparece el vínculo entre grupos insurgentes y narcotráfico, donde este último funciona como el aparato financiero de los primeros. Es acá donde la extradición empieza a ser aplicada fuertemente a actores que antiguamente contaban con estatus político y no eran identificados con el narcotráfico, como diferentes guerrilleros o paramilitares (Zuleta, 2010).

Otro autor que se enmarca bajo esta perspectiva "mixta" es San Martin (2007). A lo largo del texto "La extradición y la Cooperación Judicial Internacional", este autor explica cómo la extradición es entendida como un mecanismo de Cooperación Judicial Internacional, el cual posee una configuración mixta entre lo penal y lo político. Esto genera una multiplicidad de factores a la hora de tomar la decisión sobre una extradición, que lleva necesariamente a entender el contexto sociopolítico e histórico además de los tratados multilaterales y bilaterales en materia del derecho internacional.

Para explicar de manera detallada su argumento central, en primera instancia determina que la Cooperación Judicial Internacional puede definirse como el conjunto de actos de naturaleza jurisdiccional, diplomática o administrativa que involucra a dos o más Estados, y que tiene por finalidad favorecer la criminalización secundaria de un hecho 
delictivo ocurrido en territorio, cuando menos, de uno de tales Estados. Además, realiza una revisión histórica de los tratados multilaterales y bilaterales del Estado peruano, con la intención de desglosar y entender las implicaciones existentes en un tratado de extradición, dependiendo de los actores estatales involucrados. Todo lo anterior bajo la guía del Derecho Internacional pero haciendo las distinciones del objetivo político de dicha herramienta de Cooperación Internacional (la extradición). Finalmente plantea que a nivel contemporáneo la extradición es considerada como una institución de naturaleza jurídica y como un acto político. La naturaleza política de la extradición se vincula con el interés político; como tal, corresponde al Estado requerido valorar si la extradición es, además de jurídicamente posible, políticamente conveniente. Aclarando que su enfoque tomara en cuenta tanto elementos internos como externos en el momento de tomar las decisiones en materia penal y política.

Por otro lado, Tickner (2000) presenta una postura de doble vía, es decir, Colombia ha oscilado entre dos enfoques principales en sus relaciones con Estados Unidos: una total subordinación y la autonomía relativa (p.40). La afirmación de la autora es interesante, y se sustenta en un recorrido histórico que hace de diferentes periodos presidenciales, principalmente entre Samper y Pastrana, pero retomando aspectos de los anteriores gobiernos. El análisis es diciente, y muestra cambios importantes en la política internacional de Colombia: en momentos era Respice pollum, y en otros Respice similia, esto cambiaba de acuerdo al gobierno de turno. A pesar de que el análisis que la autora hace es muy relevante, en el presente escrito, se enfoca en hacerle seguimiento al tema de la extradición en la relación entre Estados Unidos y Colombia en el marco de la lucha antidroga. La autora muestra que en Colombia el tratado acerca de la extradición ha estado presente a lo largo del tiempo, pero se ha apelado a él en los momentos más coyunturales, por ejemplo: después de la muerte de Rodrigo Lara Bonilla, y posterior a la Constituyente Nacional (en donde se prohibía la extradición) pero por el aumento de la violencia se vuelve a apelar a ésta. Es decir, el tratado de extradición en Colombia ha sido utilizado como un mecanismo para el gobierno colombiano para mostrarse fuerte nacionalmente, e internacionalmente como actor que está en contra de la lucha ante las drogas.

Con todo lo anterior, y luego de esta revisión bibliográfica en la que notamos que muchos autores comparten ideas y conceptos, se cree pertinente abordar la extradición a 
partir de los autores cuya apuesta analítica se centra en los factores internos que llevan a desarrollar la extradición como parte de la política exterior colombiana.

Se decide optar por esta posición por tres razones fundamentales. Por un lado, el énfasis en lo interno nos permite analizar y constatar la evolución de la extradición en relación a los diferentes cambios en el ejecutivo (principalmente los presidentes) y los eventos coyunturales que ayudan a explicar el cambio que se da tanto en el discurso sobre el narcotráfico como la posición respecto a la extradición.

Por otro lado, esta posición nos permite afrontar la idea de que las decisiones en política exterior colombiana tiene una fuerte relación con la presión estadounidense y el carácter hegemónico de este país. Esto nos lleva a desistir de la posición que se encuentra en la segunda corriente de autores presentados con anterioridad. Sin embargo, y pesar de que hay una coherencia evidente entre la política contra las drogas y el terrorismo entre Estados Unidos y Colombia, se considera que la extradición, según lo que algunos autores establecen, no ha sido un continuo inequívoco, sino por el contrario ha evoluciona, mostrando rupturas y continuidades.

Finalmente, esta posición, junto a las anteriores razones, permite plantear una pregunta de investigación que guie una nueva concepción de la extradición: ¿En qué medida la extradición es una herramienta útil del Estado colombiano para la extracción de recursos a nivel internacional y, a su vez, también es útil para mejorar su imagen estatal?

Se propone una hipótesis inicial a partir del modelo constructivista que recupera elementos del racionalismo (realismo) usado por Sandra Borda para explicar la resistencia del gobierno estadounidense a cambiar su enfoque sobre la problemática de las drogas (Borda, 2002) y la internacionalización del conflicto colombiano (Borda, 2007). Una posible hipótesis que resulta de la revisión y de la aplicación de este modelo es que la extradición, como mecanismo de política exterior, funciona, por un lado, como una herramienta para fortalecer la imagen del Estado colombiano en momentos en que su identidad se ve afectada por crisis de orden público y coyunturas políticas que lo ponen en una posición incómoda a nivel interno y externo (ángulo constructivista de su trabajo), y, por otro lado, esta decisión representa beneficios a nivel material y sistémico que ayudan a aumentar el poder de Colombia, principalmente provenientes de Estados Unidos, posibilitándole al Estado afrontar con mayor comodidad las crisis de orden público (ángulo racional de su trabajo). 
Para lo anterior, entenderemos identidad nacional a partir de la propuesta conceptual de Robles (1996) donde la identidad aparece como el fundamento de la imagen nacional la cual se define como una red de valores, creencias y cualidades culturales que permiten distinguir a un Estado de otro en el sistema internacional, y por lo tanto permite un ejercicio de predicción respecto a lo que cada uno es. La propuesta de Robles se entiende además por el peso la identidad nacional en la política exterior. Menciona el autor que la política exterior es una de las herramientas principales que existen para proyectar una identidad, y que las decisiones que se tomen en este tipo de políticas, aunque limitadas por factores internos, permiten hacer un ejercicio de proyección. Esto es caracterizado por el autor el papel de la imagen nacional como actor activo de la política exterior, donde esta dinámica entre estas dos variables está en función del cumplimiento de unos objetivos específicos.

Es acá donde se debe hacer una aclaración. La posición que establece los factores internos y externos como fundamentales para entender la extradición, será retomada a partir de alguno de sus elementos pero no necesariamente fundamenta la hipótesis inicial. Esto porque cuando se indican los momentos de crisis del Estado colombiano (respecto a su identidad y la idea de fortaleza), la presión externa es innegablemente importante para entender la cuestión. Sin embargo, la idea que se desea presentar, es que esta presión no es una imposición de los Estados Unidos per se, sino que nace de la lectura que hace el gobierno colombiano de las posibles consecuencias a nivel internacional en caso de que su identidad y su poder se vean afectados. Por lo tanto, la presión internacional se entiende por la percepción misma del Estado colombiano y no por la imposición y poder hegemónico de los Estados Unidos.

La selección de Colombia como un caso de estudio está motivada por varias razones. Por un lado, varios autores concuerdan que Colombia es uno de los Estados que más tratados sobre extradición ha firmado (Buitrago, 2006) y, además, el debate alrededor de este tema ha sido una constante desde la década de 1980 (Nullvalue, 1997). Por otro lado, y como se ha mencionado anteriormente, el narcotráfico y el conflicto armado han sido uno de los factores más influyentes en la formulación de la política exterior colombiana, así como el establecimiento de la agenda internacional (Tokatlian, 2000). Esto hace que Colombia sea un caso atractivo para abordar la extradición a partir de las dinámicas que constituyen la política exterior de este caso. Finalmente, se encuentra que la extradición es 
un tema vigente en la actualidad, ya que, por ejemplo, únicamente durante el 2016 se han extraditado a más de 27 colombianos (Joanpa, 2016), además de que el debate respecto a la posible extradición de los jefes guerrilleros ha generado un debate interesante en clave del proceso de paz actual. ${ }^{1}$

La elección de los periodos a abordar también responde a razones particulares. Como se reveló en la revisión bibliográfica, la extradición moderna aparece a inicios de la década de 1980 con la firma del tratado entre Colombia y Estados Unidos, el cual ingresó directamente al ordenamiento jurídico colombiano. Sin embargo, el constante choque de poderes y el debate respecto a esa metería llevaron a que para el año de 1986 y 1987 la Corte Suprema declarara inconstitucional este tipo de acciones. Sólo es hasta 1997 cuando aparece una nueva legislación que permite nuevamente la extradición de nacionales (González, 2015). Lo anterior explica por qué no se abordan los periodos presidenciales de Cesar Gaviria (1990-1994) y Ernesto Samper (1994-198), pues ninguno de éstos contó con esta herramienta. Además, la escogencia de periodos que corresponden a dos décadas diferentes nos permite generar un contraste, y así, visualizar las continuidades y las rupturas que se han dado respecto al tema en relación a los discursos y la extracción de recursos. Finalmente, existe una cuestión metodológica respecto al acceso a la evidencia empírica que sustenta la hipótesis. Se ha logrado reunir información importante respecto al tema, y principalmente respecto a los presidentes, pero no respecto a otras instituciones como el Congreso y las diferentes embajadas, por lo que ampliar el trabajo sería ir más allá de los objetivos y posibilidades iniciales.

A continuación se analizarán los periodos presidenciales mencionados, y por medio de la evidencia empírica, se intentará establecer un dialogo entre los discursos que fundamenta la identidad del Estado con las cifras que demuestran el acceso y extracción de recursos a nivel internacional.

\section{Belisario Betancourt (1982-1986) y Virgilio Barco (1986-1990)}

Le decisión de abordar estas dos presidencias juntas responde a dos razones esencialmente. Por un lado, estos dos presidentes, a pesar de que son los precursores de la extra-

1 Véase por ejemplo el debate alrededor de la no extradición de Juan Vicente Carvajal, miembro de las FARC capturado en el 2015 (Semana, 2015). 
dición modernas, no iniciaron sus periodos administrativos aceptando dentro de su política internacional la extradición como una de sus herramientas principales. En contraste con lo anterior, estos presidentes intentaron proyectar una imagen internacional independiente, intentando formular su política exterior con un énfasis especial en los países con situaciones similares o no alineadas políticamente (de manera oficial) (Tokatlian, 2000) (Palacios, 2012). Por otro lado, como se podrá ver durante el desarrollo de la investigación, a nivel nominal estos presidentes extraditaron considerablemente menos personas que durante los otros dos periodos analizados. Sin embargo, hay que hacer la aclaración que los contextos eran totalmente diferentes.

Se puede afirmar que durante estos dos periodos se desarrollan dos procesos que están relacionados sensiblemente con varias crisis internas de orden público. El primer proceso, que ya se ha mencionado, está relacionado con el intento por formular una política externa más independiente de los poderes hegemónicos de la Guerra Fría (Palacios, 2012). Evidencia de lo anterior es el papel que jugaron estos presidentes en la formación del Grupo de Contadora, el Movimiento de Países No Alineado, los acercamientos con países como Cuba y la conformación del Grupo de Rio (Tokatlian, 2000). Sin embargo, este intento por independizar la posición de Colombia en el sistema, incluyendo la no extradición de los nacionales, tiene una primera crisis con el asesinato del ministro de justicia de Betancourt, Rodrigo Lara Bonilla, en 1984. Esto lleva a declarar el Estado de Sitio por medio del Decreto 1038 de 1984, que, entre otras cosas, habilitaba nuevamente la extradición de ciudadanos colombianos (Núnez, 2013). Este segundo proceso, que Núñez (2013) llama como securitización, está compuesto básicamente de un cambio discursivo donde se denuncia públicamente la existencia de un fenómeno o grupo de personas que pone en grave riesgo la seguridad de la población y del Estado Colombiano. Este viraje queda constatado en el discurso declarado el 4 de abril de 1985, durante la visita de Belisario Betancourt al presidente de Estados Unidos, Ronald Reagan:

We understand that the gravity of the problem is a consequence of both illegal production and distribution of drugs as well as growing demand (...). For these reasons, each government is prepared to assume its responsibilities, eliminating both illegal production and drug abuse. 
The United States recognizes the effort, the commitment of resources and the sacrifices that Colombia has made in destroying crops and laboratories, seizing shipments and bringing suspected drug traffickers to justice, including the extradition of traffickers accused of narcotics crimes in the United States (...).

We are in entire agreement on the need to continue these intensified efforts and to ensure the closest possible collaboration in the war against narcotics. Both nations reaffirm respect for our mutual legal obligations to extradite traffickers under our existing treaty, and will remain in close contact to periodically examine and improve the framework of our legal and law enforcement cooperation as necessary (...).

Colombia renews the commitment to fight against drug trafficking at all levels in order to destroy the crops, the laboratories where drugs are processed, to interrupt the transportation to the U.S. market and to see that those responsible for the trafficking are severely punished (...).

The cost of success in the past has been high. It has included the life of a Colombian Cabinet Minister, Rodrigo Lara Bonilla, and law enforcement officers from both countries. We cannot allow such sacrifices to have been in vain. We pledge to each other to revitalize and intensify our efforts to destroy the trafficking network. Our decision is irreversible, our dedication total. Nothing will deter us from this fight (Peters, 1985).

El discurso no sólo es un claro acercamiento de Colombia a los Estados Unidos, sino que también demuestra que el Estado colombiano deseaba aumentar su compromiso frente a este tema (dándole un viraje a la identidad nacionalista que se quería construir), a cambio no sólo de apoyo político, sino también del consiguiente apoyo económico directo e indirecto, que queda consignado en la tabla 1 presentada adelanta, y que recopila el aumento considerable de los prestamos e inversiones extranjeros que vivió el país a partir de lo que se ha llamado el proceso de certificación sobre la lucha contra las drogas (Pardo \& Cardona, 1995). Este proceso culminó con la extradición de seis ciudadanos colombianos en los últimos anos de la presidencia de Betancourt, finalizando con la aprobación de la ley 30 de 1986 que penalizaba absolutamente toda actividad relacionada con las drogas (Ramírez, 2013). 
Por su lado, Virgilio Barco quien también deseo implementar estrategias alternas e independientes en su política exterior (Núnez, 2013), pero los continuos asesinatos de funcionarios públicos y miembros de la fuerza pública, llevaron a que este presidente retomara el uso del Estado de Sitio e implementara decretos como el 3665 de 1986 que le daba potestades especiales a los cuerpos de seguridad para que adelantaran acciones contra el narcotráfico (Núnez, 2013). Sin embargo, la Corte Suprema de Justicia declara inexequible la ley 27 de 1980 que introdujo en el ordenamiento jurídico colombiano la extradición (Ramírez, 2013). Barco responde a formulando la ley 6 de 1986, que posteriormente, por vacíos jurídicos termina habilitando la extradición por vía administrativa (Redacción, 1997).

Durante este proceso de tensiones entre el ejecutivo y el aparato judicial colombiano, Estados Unidos adelantó varias medidas que generaban un ambiente de presiones alrededor del tema. La restricciones de visados y la invitación a los miembros de la OEA para aumentar los aranceles a productos colombianos, llevaron a que Colombia rápidamente extraditara para el ano de 1989 a más de 14 colombianos (Bedoya, 2006). Este intento por contrarrestar las presiones externas sumado la búsqueda de recursos, queda en evidencia con el discurso pronunciado el 28 de septiembre de 1989, durante una de las visitas de Barco a Estados Unidos, luego de la muerte de Luis Carlos Galán a manos del narcotráfico y la posterior conmoción interna.

"Esta tarde vengo a hablarles de una guerra que está muy cerca de sus fronteras - una guerra que llega a lo más profundo de las calles de Washington y de todas las otras ciudades de este pais (...)

Como ustedes saben mi país está en guerra. Y he venido hoy como lo hubiera hecho un aliado de una de las guerras anteriores, para advertirles sobre algo que posiblemente no ven plenamente. Nuestros dos gobiernos han incrementado notablemente los esfuerzos para combatir la empresa criminal de los narcóticos. Esta ha absorbido más y más atención y recursos de nuestros dos gobiernos. Comprendemos que solo si actuamos unidos podremos ganar esta guerra.

Sin embargo, en estas últimas semanas se ha perdido la esperanza de que este flagelo se pueda combatir como un severo problema legal y de orden público. Todos ustedes saben del sacrificio que muchos colombianos han hecho -y que están dispuestos a con- 
tinuar haciendo- en esta guerra. No me detendré contabilizando los innumerables actos de terrorismo. Pero ustedes pueden entender por la situación que está pasando mi país.

Hace seis semanas, Luis Carlos Galán, uno de los candidatos presidenciales con más opción y una figura sobresaliente de la nueva generación de dirigentes políticos, fue asesinado por los carteles de la droga porque persistía en hablar en su contra (...).

Sin embargo, en su muerte reposa parte de su testamento politico. Él nos ha unido. Los colombianos tenemos la determinación de acabar con esos asesinos (...).

Ahora les diré especificamente qué necesitamos para ganar la guerra y qué es lo que no necesitamos. Contra el narcotráfico. Asi también reafirma la legitimidad de Colombia en el exterior como un defensor de la moral y la lucha contra las drogas.

Dentro de las peticiones se encuentra aquella de no tomar medidas contra la economía de los países que "sufren" del tráfico de drogas, pues dichas acciones contribuyen a la debilidad de los Estados para combatir las drogas. Al tiempo se convierte en un "garrote" que no beneficia la lucha.

Agradecemos la pronta ayuda prestada por los Estados Unidos (...).

Hablaré sobre la ruptura del Pacto Cafetero Internacional, que le costará a Colombia 400 millones de dólares en ingresos este año y de la necesidad de apoyar el desarrollo económico legítimo si queremos acabar con las economías ilegales como la de las drogas (Presidencia de la República, 1990).

Este discurso, donde particularmente Barco intenta darle una dimensión internacional al problema del narcotráfico, resaltando la necesidad que tiene Colombia de recibir ayuda para afrontar este flagelo en un momento donde el Estado se ve en jaque, culminó con la aprobación casi inmediata de 65 millones de dólares más el aporte técnico a la fuerza pública (Núnez, 2013), lo cual, en términos racionales, es una ganancia no sólo porque inicia un proceso de ayuda económica, sino que también está respaldado por el discurso político oficial de Estados Unidos² donde se empieza a construir una identidad de Co-

2 Véase por ejemplo el discurso de George H. W. Bush el 25 de agosto de 1989 donde aprueba la ayuda militar y económica (citar). 
lombia como país que colabora y lucha mano a mano contra los carteles y el fenómeno transnacional del narcotráfico.

Finalmente, como ya se mencionaba, la ayuda económica también se empieza a dar de manera indirecta. Gracias al proceso de certificación, el flujo de préstamos e inversión extranjera vivió un considerable aumento durante estas dos presidencias:

\section{Tabla 1}

Préstamos internacionales a Colombia (1981-1991)

$\begin{array}{lrrrrrrrrrrr}\text { Prestamista } & 81 & 82 & 83 & 84 & 85 & 86 & 87 & 88 & 89 & 90 & 91 \\ \begin{array}{l}\text { Banco } \\ \text { Mundial }\end{array} & 1,105 & 1,153 & 1,43 & 1,576 & 2,397 & 3,528 & 4,111 & 3,899 & 3,806 & 3,859 & 3,728 \\ \text { BID } & 623 & 686 & 654 & 768 & 1,010 & 1,299 & 1,660 & 1,703 & 1,839 & 2,139 & 2,427 \\ \text { Otros } & 35 & 54 & 55 & 46 & 43 & 39 & 36 & 32 & 29 & 23 & 20 \\ \begin{array}{l}\text { Total } \\ \text { multilateral }\end{array} & 1,763 & 1,893 & 2,139 & 2,392 & 3,450 & 4,596 & 5,807 & 5,634 & 5,674 & 6,021 & 6,175\end{array}$

Fuente: Goncalves (2002).

Nótese cómo evolucionan constantemente los préstamos económicos recibidos por Colombia a través de varias instituciones internacionales. Con esto no se quiere decir que Colombia haya requerido préstamos por cuestiones ligadas a la extradición o a la lucha contra el narcotráfico. Lo que se desea evidenciar acá, es como el paulatino cambio en la identidad internacional de Colombia, soportado en nuevas percepciones y discursos, permiten ampliar el apoyo que recibe este país, por parte de actores centrales como Estados Unidos, frente a este tipo de organismos, logrando acceder a más recursos a lo largo del tiempo.

\section{Andrés Pastrana Arango (1998-2002)}

La política exterior colombiana entre 1998-2002, en cabeza de Andrés Pastrana Arango, se vería fuertemente influenciada por la búsqueda del fin del conflicto colombiano. Pastrana se posesiona con el fin de concretar los diálogos con las FARC que se realizarían en cinco municipios del país, que se conocerían como la zona de distensión del Caguán. En la mente de Pastrana Colombia no sería un actor que solo buscaba cooperación in- 
ternacional sin dar nada a cambio: "no queremos ser espectadores simples sino protagonistas diligentes de ese nuevo compromiso mundial (...) Nuestra política exterior estará encaminada a fortalecer nuestro poder de negociación en torno a temas primordiales de la agenda global" (Discurso de Pastrana, 1998)

Pastrana cuando inició su gobierno "estableció una clara distinción entre los intereses y prioridades colombianos, los cuales giraban en torno a la negociación de la paz con las FARC, y los imperativos estadounidenses en el país, basados esencialmente en el problema de las drogas ilícitas" (Tickner, 2007:99) Las negociaciones en el Caguán y la política exterior que promovería Pastrana encontraría en la diplomacia por la paz y el Plan Colombia una forma de internacionalizar el conflicto (Tickner, 2007) Él estaba pensando el conflicto en dos vías: lograr firmar el acuerdo con las FARC, o ante un eventual fracaso, tener unas mejores Fuerzas Armadas para enfrentar a este grupo, por lo cual apeló a la modernización de éstas.

El discurso del presidente Pastrana era luchar contra las drogas ilícitas y el terrorismo y el narcotráfico, pero también fortalecer el área social: "es el compromiso del gobierno colombiano seguir luchando contra las drogas (...) necesitamos ayuda de Estados Unidos y de Europa (...) seguiremos comprometidos con la lucha del terrorismo y el narcotráfico (...)" Y bajo la lógica de atacar el narcotráfico aparecería la no poca cantidad de 78 colombianos extraditados a causa de relación con narcotráfico (Extradición en Colombia y el mundo, 2013). En el discurso la lucha contra el narcotráfico era de vital importancia ya que este era uno de los principales problemas en la terminación del conflicto.

En este gobierno se propuso en la búsqueda de "recursos, hardware y la capacitación requerida para combatir la naturaleza cambiante del narcotráfico" (Pastrana, 2000). Hay una gran preocupación por parte del gobierno en su estrategia por "desterrar a los narcotraficantes y a la violencia que estos le han impuesto a la sociedad y economía” (Pastrana, 2000). También se resalta que en Colombia ya se han dado operativos previos para apelar a la extradición: en la operación Milenio, arrestamos treinta de los más poderosos narcotraficantes en Colombia y en otras partes del mundo, algunos de los cuales ya han sido extraditados a los Estados Unidos. Y con ello enviamos un claro mensaje a aquellos que siguen delinquiendo: el narcotráfico jamás será tolerado en Colombia, y estamos decididos a destituirlos a ellos y su imperio (Pastrana, 2000). 
En el plan Colombia, Andrés Pastrana encontraría ayuda económica y técnica para fortalecer su lucha contra las drogas ilícitas. Del gobierno de Estados Unidos recibió un paquete de asistencia por $\$ 1.300$ millones dólares; los cuales serían destinados para un desarrollo alternativo, asistencia a desplazados, protección a los derechos humanos básicos, gobernabilidad y reforma del sistema judicial, apoyo al proceso de paz y apoyo a la región, apoyo a los esfuerzos de interdicción (Departamento de Estado de los Estados Unidos.2001)

Para el presidente Andrés Pastrana los diálogos del Caguán lograron gran apoyo internacional, y a pesar de que no se lograría la firma de la paz, la política exterior había logrado un gran avance. En el discurso con el cual finaliza oficialmente las negociaciones con las FARC afirma:

\begin{abstract}
"A nivel internacional hemos logrado reunir como nunca antes en nuestra historia a toda la comunidad internacional en torno a nuestro proceso de paz, apoyando a las legítimas aspiraciones de paz de los colombianos. Hoy la guerrilla está desenmascarada y ha mostrado su verdadera cara, la cara de la violencia sin razón, ante el mundo. Hoy las naciones del planeta saben que no son robin hoods que lucha por el pueblo oprimido, sino personas sin escrúpulos que no tienen problema en asesinar niños para conseguir sus fines. (...) Mi Gobierno puso en marcha, con el Plan Colombia, la estrategia de inversión social más grande de nuestros tiempos. (...) Así que no hemos perdido en estos difíciles años. Al cabo de todo, si hacemos un balance objetivo, hoy estamos más preparados que nunca, más unidos que nunca, respetados y apoyados internacionalmente y más fuertes militarmente para enfrentar la violencia que nos agobia." (Pastrana, 2015)
\end{abstract}

La internacionalización del conflicto a la que apela el gobierno de Andrés Pastrana trajo con sí el apoyo en un principio para apoyar las negociaciones con las FARC, pero a la vez, buscó la manera de modernizar sus fuerzas armadas, un apoyo internacional para combatir el narcotráfico. En este marco apeló a la extradición como uno de los medios para enviarle un mensaje a aquellos que seguían delinquiendo: el narcotráfico jamás será tolerado en Colombia (Pastrana, 2000). 


\section{Álvaro Uribe Vélez (2002-2006, 2006-2010)}

El enfoque discursivo del presidente Uribe consistió en adoptar un lenguaje similar al del gobierno norteamericano, fijando como una de las tareas fundamentales de la diplomacia colombiana lograr la condena de las FARC como un grupo terrorista por parte de distintos actores internacionales (Uribe, 2002). Aunque en algunos casos se trató tan sólo de declaraciones sin mayores consecuencias, en otros, la inscripción de las agrupaciones guerrilleras en las listas de grupos terroristas implicó medidas concretas de persecución a los líderes guerrilleros, el bloqueo en los espacios internacionales, y la persecución de las finanzas de origen ilícito. Además, al formar parte de la lista de organizaciones terroristas del Departamento de Estado, el garrote de la extradición aparece como una amenaza real para los líderes guerrilleros, no sólo por su participación en el tráfico ilícito de drogas, sino en relación con acciones terroristas $\mathrm{y}$ atentados a los intereses estadounidenses.

En materia de extradición, el gobierno Uribe se lleva las palmas. Desde el inicio de su mandato, el presidente Uribe manifestó su voluntad de agilizar la extradición y convertirla en una de las bases de su política criminal, así como en una muestra del firme compromiso de su gobierno con la lucha antinarcóticos. Lo anterior apoyado en un discurso donde afirmar: "El problema del terrorismo en Colombia, de la droga en Colombia que lo financia, es hoy un problema de Colombia y entraña un riesgo de contagio para todos los países hermanos. Por eso los invito a que fortalezcamos nuestras acciones de cooperación con el terrorismo. La mayor responsabilidad la tiene Colombia para evitar que estos terroristas extiendan sus actividades a los países hermanos, pero mucho nos ayudará a cumplirla en la medida que haya más y más cooperación" (Uribe, 2004). Como resultado de esto, más de 200 colombianos fueron extraditados hacia Estados Unidos durante su primer gobierno; entre ellos, doce de los más importantes hombres de la mafia. Esta cifra contrasta con las 78 personas extraditadas durante todo el mandato de Pastrana.

Esta campaña discursiva además contribuyó a reafirmar la idea de que el conflicto colombiano forma parte de la lucha global contra el terrorismo con la consecuente legitimación de la política de seguridad democrática de Uribe; contribuyó, por lo menos inicialmente, y dado el clima internacional todavía cercano a los atentados del 11-S, a bajarle el tono a las críticas por parte de algunos países y de algunas ONG internacionales 
a la estrategia de guerra del entonces presidente Uribe. Por esta misma vía se reafirmaba el alineamiento con Estados Unidos al entrar a formar parte de la coalición contra el terrorismo global (Rojas, 2006, pág. 92).

Viendo todo lo anterior cimentado en las bases del Plan Colombia, el cual contaba con $\$ 10.730$ millones de dólares para efectuar a lo largo de 6 años, condicionando el apoyo a futuro con los resultados presentados por el gobierno del presidente Uribe. Es por ello que la extradición representaba una herramienta atractiva y eficiente para estrechar lazos de cooperación y apoyo internacional, con miras a futuros proyectos como el Plan Colombia.

Tabla 2

Recursos ejecutados del Plan Colombia 1999-2005 (millones de dólares)

\begin{tabular}{lrrrrrr}
\hline Componente & \multicolumn{2}{c}{ Nacion } & \multicolumn{2}{c}{ EE.UU. } & \multicolumn{2}{c}{ Total } \\
\hline Fortalecimiento institucional & 2.387 & $22,2 \%$ & 465 & $4,3 \%$ & 2.852 & $26,6 \%$ \\
\hline $\begin{array}{l}\text { Luchas contra las drogas ilicitas } \\
\text { y el crimen organizado }\end{array}$ & 3.378 & $31,5 \%$ & 2.787 & $26 \%$ & 6.165 & $57,5 \%$ \\
\hline Reactivación económica y social & 1.185 & $11,0 \%$ & 530 & $4,5 \%$ & 1.715 & $16 \%$ \\
\hline Total & 6.950 & $64,8 \%$ & 3.782 & $35,2 \%$ & 10.730 & $100 \%$ \\
\hline
\end{tabular}

Fuente: MDN y Acción Social. Cálculos DNP DJS.

Por otro lado desde inicios de su segundo gobierno, Uribe en el llamado Plan Patriota, el cual vinculó por primera vez de manera clara y abierta a Estados Unidos en la lucha contrainsurgente colombiana. Los recursos norteamericanos se aumentaron abismalmente, e incluyeron gastos en entrenamiento, armas, repuestos, inteligencia, transporte, equipos de comunicación, entre otros. Decenas de expertos militares y contratistas cumplieron labores de planeación y soporte logístico de los operativos. Es por ello que a finales de 2004, el Congreso estadounidense decidió aumentar, de 400 a 800, la cantidad de personal militar norteamericano permitido en Colombia, así como el número de contratistas, de 400 a 600. Esta modificación en la participación norteamericana se logra entrever en el momento en que Uribe afirma que "El apoyo norteamericano dejó atrás el discurso y se convirtió en apoyo efectivo. Confiamos que los Estados Unidos y el Presidente Bush continúen con la ayuda hasta que Colombia esté libre de la plaga del terrorismo y de la droga. La tarea no la podemos dejar a mitad de camino, vamos a ganar pero aún no hemos ganado. Hemos avanzado pero la culebra todavía está viva" (Uribe, 2004). 
Sin embargo, se empezaban a notar ciertos condicionamientos para dicho apoyo norteamericano, pues a principios de febrero de 2006, el Senado estadounidense aprobó una ayuda de hasta 20 millones de dólares para financiar el proceso con los paramilitares, exigiendo que Colombia cooperara con la extradición de éstos para poder hacer efectiva la ayuda. Por tal motivo la extradición se convierte en un elemento fundamental para lograr captar ayudas internacionales, ya que demuestra el compromiso en términos de cooperación judicial internacional (González, 2015).

Además, el Plan Colombia que estaba contemplado originalmente para seis años, hasta el 2005, se prolongó por un año más casi de manera inercial hasta que a principios de 2007 el gobierno de Álvaro Uribe en su segundo mandato presenta la Estrategia de Fortalecimiento de la Democracia y del Desarrollo Social 2007-2013, la cual se asume como la fase II del Plan Colombia. Esta profundización se reflejaría tanto en el hecho de que la EFDDS abarcó la mayoría de los temas de la acción del estado como en el presupuesto presentado para financiar el conjunto de la estrategia; el costo total se estima en US\$ 43.836,6 millones de dólares comparados con el costo total del Plan Colombia 1 que ascendió a US\$10.732 millones como bien se puede observar en la tabla 2 (Rojas, 2007).

\section{Tabla 3}

Esfuerzo colombiano por componente de la Estrategia de Fortalecimiento de la Democracia y el Desarrollo Social (2007-2013) (millones de dólar)

\begin{tabular}{|c|c|c|c|}
\hline Componente & Nación & EE.UU. & Total \\
\hline Fortalecimiento a la Justicia y DDHH & & 2.749 & $6 \%$ \\
\hline Lucha contra el terrorismo y el narcotrafico & & 6.172 & $14 \%$ \\
\hline Internacionalización económica & & 12.000 & $27 \%$ \\
\hline Social & & 20.661 & $48 \%$ \\
\hline Atención a la población desplazada & & 1.201 & $3 \%$ \\
\hline Reintegración & & 1.045 & $2 \%$ \\
\hline Total & & 43.836 & $100 \%$ \\
\hline
\end{tabular}

Fuente: Marco de Gastos de Mediano Plazo (MHCP). Calculo: DNP

Es en este punto donde llama la atención, el aumento de cerca del 400\% en el presupuesto de ayuda norteamericana. Una de las explicaciones más palpables es que la estrategia del gobierno Uribe logro de una u otra forma estrechar los lazos en la lucha contra las 
drogas y el terrorismo, demostrando a través de los múltiples golpes a estas organizaciones y de la voluntad de permitir que fueran juzgados en el extranjero, una real y más notoria alianza con los estadounidenses. Lo cierto, es que el apoyo se vio retribuido a lo largo del segundo gobierno de Álvaro Uribe Vélez, al notar un aumento significativo en el número de extradiciones por año pasando de 485 extradiciones entre el año 2000 y el 2006 a 736 entre el 2006 y el 2010 como bien se puede observar en el gráfico 1.

\section{Gráfico 1}

Evolución de la Extradición - Principales países de destino y delitos-2000-2011
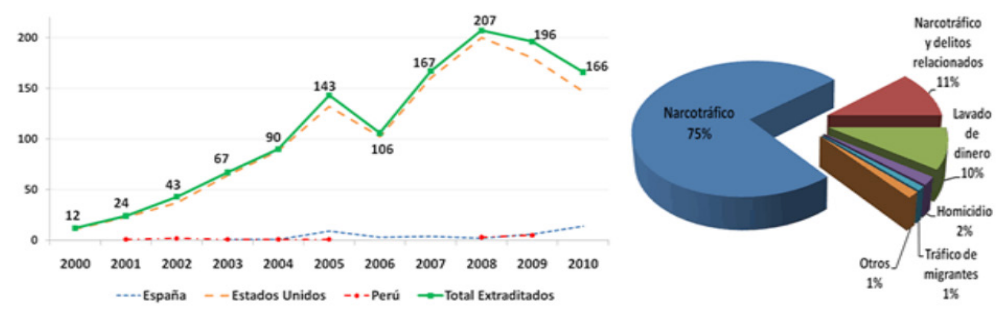

Fuente: Ministerio del Interior y Justicia, 2011

En retrospectiva la decisión de guiar la política exterior en función del conflicto armado ha tenido efectos paradójicos, pues ha resultado una estrategia exitosa para lograr respaldos internacionales a la política de seguridad, sin los cuales sería casi imposible solucionar el conflicto armado dadas las interdependencias de los factores que alimentan la guerra y de las características del propio Estado colombiano; pero ha abierto las compuertas a una mayor injerencia externa tanto en la dinámica misma del conflicto como en sus posibles soluciones, con lo cual aparecen todas las posibilidades pero también todos los riesgos que implica "internacionalizar" la política doméstica. Ya que, si bien logramos un aumento significativo en el apoyo financiero y militar, Colombia debe ceder al momento de juzgar a los directos responsables de algunos de los flagelos que más aquejan a sus ciudadanos, condicionando de esta forma la estrategia de su PE con la cantidad de veces que pueda realizar un intercambio entre apoyo financiero y extradiciones relacionadas con el delito del narcotráfico. 


\section{Conclusiones}

Durante esta investigación se intentó abordar la extradición desde una dimensión constructivista y racionalista (realista), para de esta forma mostrar como este tipo de decisiones en materia de política exterior intentan, por un lado, fortalecer la imagen del Estado en la arena internacional, y por otro lado, extraer recursos materiales por medio de compromisos y la implementación de políticas en temas de seguridad nacional.

Se considera que los aportes más relevantes de esta investigación para el estudio de la extradición y la política exterior colombiana, se pueden resumir en dos aspectos. Por un lado, logra retomar los debates y aportes más relevantes sobre la unidad de análisis, donde se resalta que la extradición como elemento de la política exterior ha sido poco abordada. En este sentido, esta investigación intentó demostrar que la extradición es un elemento central en la formulación de la política exterior, donde se puede concluir que es una condición necesaria más no suficiente para que el Estado colombiano logre sus objetivos a nivel internacional. Por otro lado, se confirma la idea que autores como Tokatlian (2000), Palacios (2012) y Tickner (2000), han trabajado, donde se afirma que uno de los elementos más particulares, más no exclusivos, de la política exterior colombiana es su fuerte dependencia al presidente de turno, donde el cambio en el ejecutivo conlleva a una importante restructuración de las relaciones y decisiones del Estado en materia internacional.

Sin embargo, esta investigación por sus alcances y su enfoque, deja varios vacíos para tener en cuenta. Inicialmente se reconoce que solo se abordaron los discursos pronunciados desde los presidentes colombianos. Para confirmar una hipótesis más amplia sobre la extradición, es relevante que en estudios posteriores se aborden las dos partes que componen este tipo de decisiones. De esta forma se ve una lógica de acción-reacción mucha más clara. En clave de esto, también se recomienda profundizar en cómo la extradición afecta las relaciones de Colombia con países que no son fuente importante de recursos materiales. Acá se podría abordar la extradición con países de la región junto a sus implicaciones

Un segundo vacío es que no se analiza el impacto de la extradición frente a los objetivos oficiales de ésta. La lucha contra el narcotráfico y el terrorismo pueden ser analizados en clave de cómo políticas como la extradición generan resultados y hacen parte de las tácticas oficiales de la fuerza pública. Esta cuestión permite evaluar la eficacia de estas decisiones. 
Por último, esta investigación intenta proponer nuevos temas para la agenda de investigación y debate de la disciplina de política exterior. En un primer momento, se propone que se realicen trabajos comparados que tengan entre una de sus variables la existencia de tratados, acuerdos o decisiones sobre extradición, para analizar el impacto de estas políticas en Estados con circunstancias y condiciones diferentes. En un segundo momento, se propone que se realicen estudios de casos, no solo sobre los Estados, sino también sobre la importancia y particularidades de los individuos extraditados. Véase, por ejemplo, como la extradición de paramilitares tiene una lógica interna diferente a los primeros narcotraficantes extraditados, o como la extradición de individuos con alto perfil criminal, como Joaquín Guzmán, generan importantes debates, no solo frente a la opinión pública, sino también en las altas esferas de decisiones ejecutivas.

\section{Bibliografía}

Borda, S. (2007). La internacionalización del conflicto armado después del 11 de Septiembre: ¿la ejecución de una estrategia diplomática hábil o la simple ocurrencia de lo inevitable?. Colombia Internacional, No.65, 66-89.

Borda, S. (2002). Una aproximación constructivista a la guerra estadounidense en contra de las drogas. Colombia Internacional, No. 54, 73-102.

Buitrago, R. (2006). La Política Exterior colombiana en el siglo XX. Un breve repaso histórico a nuestra política internacional. Suma administrativa, Vol. 1, 111-131.

Colombia, C. d. (Diciembre de 2014). Cancilleria. Obtenido de http://www.cancilleria. gov.co/sites/default/files/guia-practica-sobre-la-extradicion.pdf

González, E. (2015). Acuerdo bilateral entre Colombia y estados unidos, para la entrega de nacionales por comisión de conductas delictivas dentro del marco de cooperación internacional. Análisis sobre la perdida de la proporcionalidad y reciprocidad. Tesis de Grado. Bogotá D.C., Colombia: Universidad Católica de Colombia.

Joanpa. (24 de Febrero de 2016). Dos fichas del "clan Úsuga", extraditados a Estados Unidos. Recuperado de: http://www.joanpa.com

López, C. (2012). Y refundaron la patria... Bogotá: Penguin Random House Grupo Editorial.

Nullvalue. (20 de Junio de 1997). La historia jurídica de la extradición. El Tiempo . 
Palacios, M. (2012). Paz Cuatrienal. En M. Palacios, Violencia pública en Colombia, 1958-2010 (págs. 137-183). Bogotá: Fondo de Cultura Económica.

Pardo, D., \& Cardona, D. (1995). El procedimiento dé la Certificación y las relaciones entre Colombia y Estados Unidos. Colombia Internacional No. 29, 1-6.

Semana. (2015). El presidente Santos niega la extradición de un guerrillero de las FARC a EE.UU. Revista Semana .

Tickner, A. (2000). Tensiones y consecuencias indeseables de la política exterior estadounidense en Colombia. Colombia Internacional, No.50, 39-62.

Tokatlian, J. (2000). Colombia en guerra: las diplomacias por la paz. En J. Tokatlian, Globalización, narcotráfico y violencia, siete ensayos sobre Colombia (págs. 197-246). Bogotá: Norma.

Zuleta, S. (2010). Colombia y la extradición: quo vadis? Fundación Ideas para la Paz Número 3, 1 - 10.

San Martin, C. (2007). La extradicón y la cooperación judicial internacional. Lima: OEA.

Moreno, A. (2012). Una reflexión crítica sobre la extradición en colombia como debilidad del sistema judicial y politico. Encrucijada Americana, 51-56.

Rojas, D. M. (2006). Balance de la política internacional del gobierno Uribe. Analisis político, 85-105.

Rojas, D. M. (2007). Plan Colombia II ¿Más de lo mismo? Colombia internacional, No. $65,14-37$.

Uribe, A. (2002). Discurso: retomemos el lazo unificador de la ley, la autoridad democrática, la libertad y la justicia social. 07 de agosto (Bogotá)

Departamento de Estado de los Estados Unidos. (2001). Apoyo de los Estados Unidos al Plan Colombia Departamento de Estado de los Estados Unidos.

Tickner, Arlene. (2007). "Intervención por invitación. Claves de la política exterior colombiana y de sus debilidades principales", Colombia Internacional, No. 65, enero-junio, pp. 90-111.

Pastrana, A (2015). Alocución Presidencial sobre el final del proceso de paz- 20 de febrero del 2002. Recuperado de: https://www.youtube.com/watch?v=F1Z0qQfiNK0 
Ideas paz (1998). Discurso de posesión como Presidente de la República del Doctor Andrés Pastrana Arango (Bogotá D.C., Agosto 7 de 1998). Recuperado de: http:// www.ideaspaz.org/tools/download/51314

Ideas paz (2000). Discurso pronunciado por el presidente de Colombia, Andrés Pastrana Arango, ante la sociedad Americana de Directores de Periódicos en Washington, (E.U.), 12 de abril de 2000. Recuperado de:http://www.ideaspaz.org/tools/down$\operatorname{load} / 51404$

Uribe, A. (2004). Discurso: visita del presidente de estados unidos de américa george bush. Noviembre 22 (Cartagena de Indias - Bolívar)

Uribe, A. (2004). Discurso: intervención ante el consejo permanente de la OEA--- Jueves, Marzo 25 (Washington) 